\title{
TWO YEARS EXPERIENCE OF OPERATIONAL AVALANCHE FORECASTING USING THE NEAREST NEIGHBOURS METHOD
}

\author{
by
}

O. Buser

(Eidg. Institut für Schnee- und Lawinenforschung, Weissfluhjoch, CH-7260 Davos, Switzerland)

\section{ABSTRACT}

An operational version of avalanche forecasting using the nearest neighbours method was given to the Parsenndienst, the safety service in the ski area of the Parsenn region. They have tested this NXD method through two winters and have now decided to acquire their own computer with a mass storage unit in order to run the programme. The forecasting is being run by the patrolmen themselves, including the input of weather and snow data, and they also update the file of avalanche and blasting activities with the details of operations, as required for ammunition accountancy. The nearest neighbours method provides the patrolmen with a list of the avalanches that have occurred on the $10 \mathrm{~d}$ in the past 20 years most similar to the day being considered. These data represent the nearest neighbours of the method's name. The men are able to interpret the list correctly without any need of instruction, and rely on getting information from it which will help them to decide when and where to use (or not to use) explosives. The method of interpretation of the information supplied is illustrated by way of four specific examples.

\section{INTRODUCTION}

The present paper discusses how best to use the results of a numerical avalanche forecasting method. With the exception of a few remarks no details of the statistical background of the method will be given, because the interested reader will find it elsewhere (Buser, 1983). At the present time we feel that it is important to extend these forecasting methods, but the question arises as to the form in which they can most acceptably be offered and as to what can be done in order to motivate people to cooperate and invest their time and money in avalanche forecasting. This paper therefore deals with human, rather than mathematical or physical, problems.

Avalanche forecasting is a rather difficult task, not only because of underlying physical problems but also because of the widely differing requirements of its potential users. The results of statistical methods are quite satisfactory from a theoretical point of view, reaching asymptotically a score of $80 \%$. Furthermore, they reveal the parameters from the available dataset most crucially connected with the occurrence of avalanches (Obled and Good, 1980) and, as a consequence, these parameters are being used in the method in operation at present. However, the probability of the occurrence of an avalanche event is not in itself of much help, because the definition of the likely event is difficult to grasp. When it becomes a matter of making use of the forecast probabilities for daily routine work nobody really knows what to do with them, or even worse, there is a possibility that an indication of degree of probability may be misinterpreted as an indication of the degree of danger.

The present method has been developed for the use of safety services in commercialized ski areas where organizations are responsible for piste safety. If we want avalanche forecasting to be useful to them we have to convince them that they will benefit in one way or another.
In order that the rather conservative people (at least in Switzerland) in these security services will accept computerized help and use it properly we have to overcome their reluctance to accept the introduction of anything new. Therefore, in addition to being scientifically correct, the method in use should also take account of the following:

Most of the men involved in avalanche control have no academic training, therefore the basic idea must be realistic and comprehensible by the application of common sense. This is important because most users of forecasts have experience of snow and avalanches and therefore want to understand on what the method is based.

It must give the men the feeling they are still important or, even better, that they have become more important than ever. The method should not tell them what to do, but it should help them to decide what to do.

We can motivate the patrolmen by demonstrating that a lot of paperwork, such as that involved in accounting, can be dealt with more quickly and more efficiently and at the same cost by the use of this method. Since no method can be of help if it is not used there must be at least one person who takes over, feels responsible, and gets really involved with it. From our experience, some of the men may be rather indifferent at first but if there is someone to lead them they will readily cooperate.

The idea of the principle of nearest neighbours, described in section 2, is very simple. Everybody seems to know with regard to weather and snowcover, what a similar day is. Unfortunately however it is unusual for anybody to be able to give a date allowing a check to be made on the avalanche activity for that day. The present method does nothing but look for the most similar days from past years. There is no need to explain how they are found because the parameters used are reasonable, and the results are convincing and are therefore accepted.

Safety services do a lot of blasting, which is a rather costly procedure, and it is not surprising that they are interested in reducing avalanche activity. Obviously, the present methods can be helpful in this, so long as all the blasting activities for similar days in the past can be recalled.

The daily routine work involved in avalanche forecasting is described $\not \mathrm{n}$ section 2 , and in section 3 we have chosen several examples from past winters in order to show how to interpret the results obtained for different situations, and section 4 deals with miscellaneous remarks, problems and conclusions.

\section{METHOD}

The method used is, in principle, a forecast based on the assumption that for the same weather and similar snow conditions avalanche activity is always the same, and also that we are able to identify the same or at least very similar situations in the past. Any one situation can be described by a state vector, its components chosen from all available measurements. In addition to this state vector other measurements may also be relevant to the problem in 
hand. In fact, we feel that with a second measuring site in the valley we could make allowances for temperature gradient, for the vertical distribution of snow depth, and for other relevant parameters.

The NXD programme looks for the most similar days, referred to as nearest neighbours, in recent years for comparison with a given day (referred to as today in this paper). At present, 20 years are being scanned, but more or fewer years will do equally well. We know the dates of the ten nearest neighbours, and for these dates the avalanche activity may be discovered from the corresponding file. It is this information that is submitted to the forecaster. Some of the important parameters, such as snow depth, radiation, are normalized so that seasonal trend is eliminated, and we account for the feeling that a day in January may seem more like a day in spring than like one in winter.

In principle a list of avalanches, or anything recorded in the file for that day, is all that need be given to the patrolmen for them this information is more meaningful than any measure of probability of an avalanche event, with their list to hand they know what to do, because their common sense and experience tells them this. The men remember the events of the past and use their knowledge and experience to act appropriately; there is no need to explain that this is exactly what the method intends them to do. If they are interested in the probability prediction, they can simply measure the length of their list; a short list means low probability.

The nearest neighbours to be listed are sorted out according to the parameter values of the day of its issue. The degree of nearness is defined as the sum of the squares of the differences for the respective parameters, and is given in the print-out (Tables I and II), together with the degree of nearness to the two previous days. As this degree of nearness is a measure of the similarity of the days, the patrolmen get an appreciation of how close the nearest neighbours are by comparing the weather for today with that of yesterday.

\section{TABLE I. OUTPUT FOR 18 DECEMBER 1987}

Ten nearest neighbours

\begin{tabular}{|c|c|c|c|c|}
\hline Month & Year & Avalanches & Nearness & $\begin{array}{l}\text { Comments on } \\
\text { avalanches }\end{array}$ \\
\hline Jun & 1971 & 0 & 8.3 & No avalanches \\
\hline Dec & 1982 & 0 & 8.3 & \\
\hline Dec & 1977 & 305 & 8.8 & $\begin{array}{l}\text { Three avalan- } \\
\text { ches north-east } \\
\text { slopes }\end{array}$ \\
\hline Jun & 1971 & 0 & 10.4 & \\
\hline Nov & 1971 & 0 & 10.4 & \\
\hline Oct & 1979 & 0 & 11.4 & \\
\hline Nov & 1973 & 0 & 12.2 & \\
\hline Jan & 1983 & 0 & 12.6 & \\
\hline May & 1971 & 0 & 12.7 & \\
\hline Nov & 1968 & 0 & 13.1 & \\
\hline
\end{tabular}

Nearness between today and yesterday

Nearness between today and day before yesterday

28.2

Avalanches for the ten nearest neighbours

Avalanches for 24 December 1977

$\begin{array}{llllr}80 & 20 & \text { Natural } & \text { North-east } & 2590 \\ \text { Schlaflaeger; noon, rain. } & & \\ 120 & 50 & \text { Ski } & \text { East } & 2700 \\ \text { Weissfluh; two } & \text { skiers slightly } & \text { carried off. } & \text { Rain. } \\ 150 & 80 & \text { Natural } & \text { North-east } & 2640 \\ \text { Weissfluh } & & & & \end{array}$

First line: Avalanche length, width, kind of release (natural ski).

Second line: Site and remarks.

There is one day with avalanches, as can be seen in the list.
TABLE II. OUTPUT FOR 2 MARCH 1988

Ten nearest neighbours

\begin{tabular}{|c|c|c|c|c|c|}
\hline Day & Month & Year & Avalanches & Nearness & $\begin{array}{l}\text { Comments on } \\
\text { avalanches }\end{array}$ \\
\hline 13 & Jan & 1979 & 900 & 7.0 & $\begin{array}{l}\text { Avalanches on } \\
\text { all aspects }\end{array}$ \\
\hline 24 & Jan & 1984 & 0 & 8.6 & $\begin{array}{l}\text { No avalanches } \\
\text { recorded }\end{array}$ \\
\hline 12 & Jan & 1979 & 900 & 11.7 & $\begin{array}{l}\text { Avalanches on } \\
\text { all aspects }\end{array}$ \\
\hline 14 & Jan & 1979 & 1900 & 13.9 & $\begin{array}{l}\text { One glide and } \\
\text { several } \\
\text { avalanches }\end{array}$ \\
\hline 28 & Nov & 1973 & 99 & 14.0 & $\begin{array}{l}\text { No records, } \\
\text { but suspect }\end{array}$ \\
\hline 28 & Nov & 1978 & 131 & 14.1 & $\begin{array}{l}\text { One avalanche } \\
\text { north-west } \\
\text { slope }\end{array}$ \\
\hline 29 & Nov & 1973 & 323 & 14.5 & $\begin{array}{l}\text { Three avalan- } \\
\text { ches south- } \\
\text { west slopes }\end{array}$ \\
\hline 17 & Mar & 1987 & 111 & 15.7 & $\begin{array}{l}\text { One avalanche } \\
\text { east slope }\end{array}$ \\
\hline 11 & Dec & 1976 & 0 & 16.2 & \\
\hline 5 & Jan & 1984 & 111 & 16.4 & $\begin{array}{l}\text { Same as } 17 \\
\text { March } 1987\end{array}$ \\
\hline
\end{tabular}

Nearness between today and yesterday

Nearness between today and day before yesterday 44.9

The values of the parameters used have, of course, to be entered before the data search can start. They are also stored, and so form the basic data for future years. Some of the weather parameters such as duration of sunshine, radiation, cloudiness for the day, have to be estimated at the time of the forecast and therefore the estimated values of the previous day have to be updated. The forecast for that time will be run, with the measured values supplied as a verification of their accuracy. Such a procedure gives the patrolmen both the necessary confidence in their estimated weather data and also a feeling for the degree of accuracy needed. After 13 values have been typed in for the day, the programme runs for about $20 \mathrm{~s}$ until the print-out is begun and $30 \mathrm{~s}$ later the complete list is available. At this point the avalanche activity file has to be updated. The essential entries are details of the avalanches of today, whether they occurred naturally or were caused by blasting, by skiers, or by other means. Any other facts of interest may also be added, such as whether or not bombing was successful, the type of ammunition used and in which sub-area it was used. Such data is required for accounting purposes.

Weather type and snow data are monitored at only one site in the main ski area and are considered to be representative of a greatly extended area beyond that. Experience shows that wind direction and amount of precipitation are likely to differ appreciably for different sites within an area, and because of this we may find a day on which we expect avalanches on all aspects of slopes, but when a closer inspection reveals that some aspects yield avalanches which are restricted to a specific site (Table II). Despite this, so long as the weather and snow conditions for the two sites are closely correlated NXD still yields correct predictions of avalanches. As yet we have not tested the extent of the area over which the predictions of a single measuring site can be extrapolated

\section{EXPERIENCE AND EXAMPLES}

Being aware of the prevailing weather conditions, patrolmen have already formed their opinions about the potential avalanche situation. They feel that at best NXD will only confirm their feelings, and they are very frequently proved right. However, they are sufficiently curious to read the avalanche report produced by NXD and 
the list provides them with extra details about a situation with which they are already familiar in general terms. On low avalanche-probability days they just wonder what strange avalanches may have occurred. As far as we know these avalanches were always disregarded, but not without some explanation, such as being in odd places or there being no snow there today. On the other hand, on days after heavy snowfall the patrolmen hardly ever began their work by looking at the NXD list, because they already know through experience what needs to be done. Only later in the day, after the situation had ameliorated, will they check the list in order to confirm that most of what they did was correct. However, when avalanches have occurred in places with which they were not so familiar, discussions start. For example, men are reminded of places where it would be useful to have a closer look, and remarks such as "I'll have to have a look at that spot ...", "I wouldn't have thought of that slope ...", "I would have behaved more carefully if I had looked at the list before I went out ...", show how much they have responded to the help offered in the prediction list. Table II illustrates how blasting activity may be reduced; we know that on at least one occasion they did not blast because the ten nearest neighbours showed no significant avalanche activity.

The situation becomes more complicated during extended periods of snowfall. The list may turn up with avalanches on slopes they have released snow only the day before. We could not identify exactly how the patrolmen proceeded in this case; it seems as if they worked in their usual way, not paying much attention to the list of potential avalanches. They did not appear to criticize the method for being useless and still want to make use of it, even suggesting new ideas for possible improvements.

The following examples have been chosen to illustrate how an avalanche forecast compares with the actual activity of the same day.

\section{Example 1: 18 December 1987}

This day was warm and rainy, the first of the winter $1987 / 88$ observed to have avalanches. These were small and occurred throughout the whole area on north-east to south-west slopes up to $2550 \mathrm{~m}$.

Amongst the nearest neighbours there is one day with avalanches, as can be seen in the list of corresponding avalanches. The third nearest neighbour, 24 December 1977, reports the same types of avalanches as were observed on the day in quotation. However, one day out of ten corresponds to a probability of $10 \%$, which is not high. A closer look at the dates of the other neighbouring days shows that most of them are days in either May/June or in October/November. Even if there had been avalanches on those days they were unlikely to be recorded, because they were simply events that nobody cared about.

A patrolman, being aware of such facts, is not worried that only one day includes a report of avalanches; he simply compares this day with the actual situation and may use his discretion in deciding whether to issue a warning to snow guides.

\section{Example 2: 2 March 1988}

For this day summarized information only is given because both the list of avalanches and the activity file are too long to be reproduced here. Figure 1 shows the observed activity for today and the activities reported for the nearest neighbours. Notice that there is only one winter out of 20 with a record of slopes that were blasted without an avalanche occurring.

Of the six avalanches reported for today, four were predicted by the nearest neighbours method and of the remaining two one was a surface glide and the other was released the previous day (nearest neighbour 17 March 1987, released on 16 March 1987). The nearest neighbours of the winter 1986/87 are of special interest because this winter is the first for which all the blasting activity has been included whether or not avalanches were released by it.

The aspects of slopes are given as they appear in the received reports, but details are not so precise as the resolution implies. The safety service appears to blast slopes even when it is not really necessary in order always to err on the side of safety. For instance, the present example shows that there was no need to blast slopes with aspects
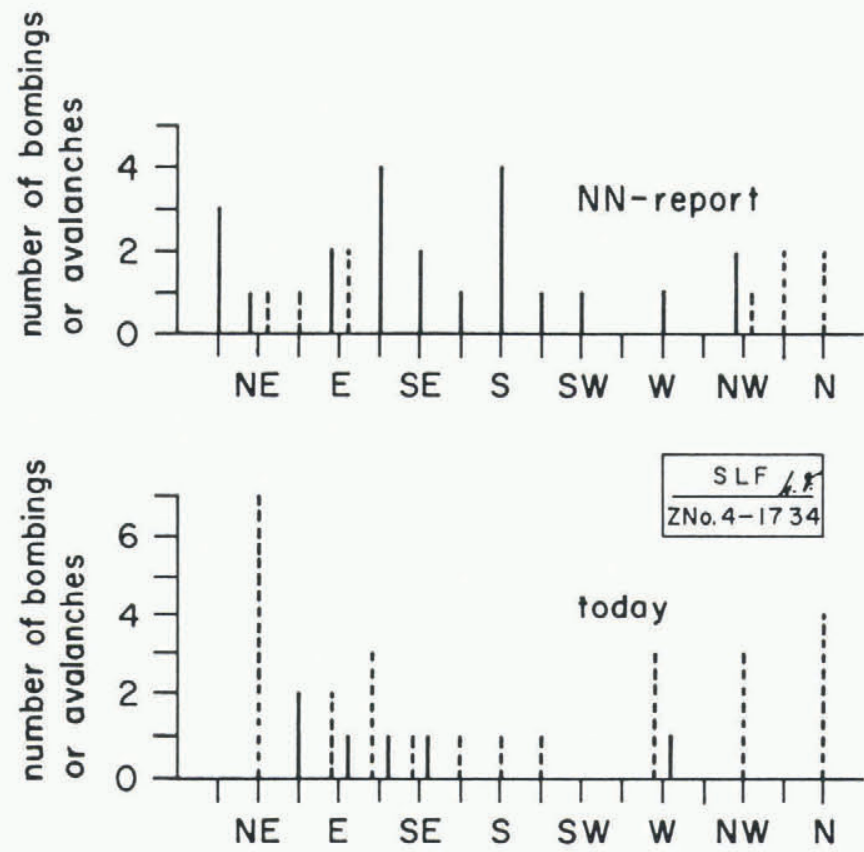

Fig. 1. Frequency of reported avalanche activities on 2 March 1988 plotted against slope aspect. Full lines: avalanche released by blasting, or naturally (n) or by skiers (s). Dotted lines: no avalanche despite blasting. $\mathrm{NN}$-report: data as given for the ten nearest neighbours.

ranging inclusively from west-south-west to north. The two sites having such aspects are along the margins of the ski area and have to be treated with this in mind. They are at the limit of the area covered by the data measuring site and show that the nearest neighbour analysis yields correct results for aspects differing from the general avalanche activity pattern on north-east to south-east slopes. The blasting of these two sites was justified, but not that of slopes with a similar aspect at other sites.
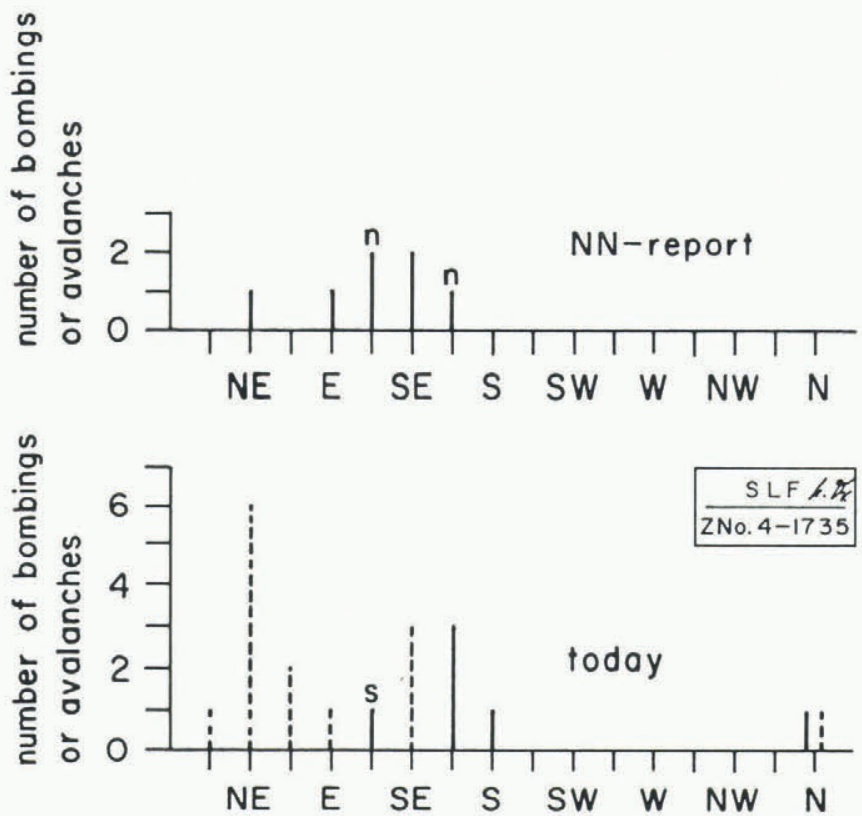

Fig. 2. Frequency of reported avalanche activities on 1 February 1988 plotted against slope aspect. Full lines: avalanche released by blasting, or naturally ( $n$ ) or by skiers (s). Dotted lines: no avalanche despite blasting. $\mathrm{NN}$-report: data as given for the ten nearest neighbours. 
Example 3: 1 February 1988

On this day there was an avalanche accident with one fatality and one person injured. The group involved was skiing off-piste. We are trying to discover more about the possibility of giving a more precise warning to avoid any similar accident in the future.

Eight nearest neighbours indicated probability of an avalanche, although two of these had no records and were simply days suspected of having had avalanches. When restricted to the Parsenn area only four avalanche days are left, three of which had had just one avalanche. The aspects of the seven avalanches are indicated in Figure 2, together with the activity of the Parsenndienst. With one exception all avalanches lay in the sector between east and south. Of the unsuccessfully blasted south-easterly slopes some were released during the previous days. The accident happened on an east-south-east slope, and we may conclude from these records that slopes of aspect between east and south are likely to prove especially tricky.

\section{Example 4: 10 March 1988}

Another fatality occurred on this day and another person was badly injured when skiing off-piste but within the Parsenn area. Four of the nearest neighbour days had a total of twelve recorded avalanches, four of them were released naturally. The accident happened on a steep north-east slope. Details concerning aspect are shown in Figure 3 .

Four out of 10 days with avalanches is not a very clear-cut situation, but it is surprising that for the four nearest neighbours three avalanches were released by skiers.
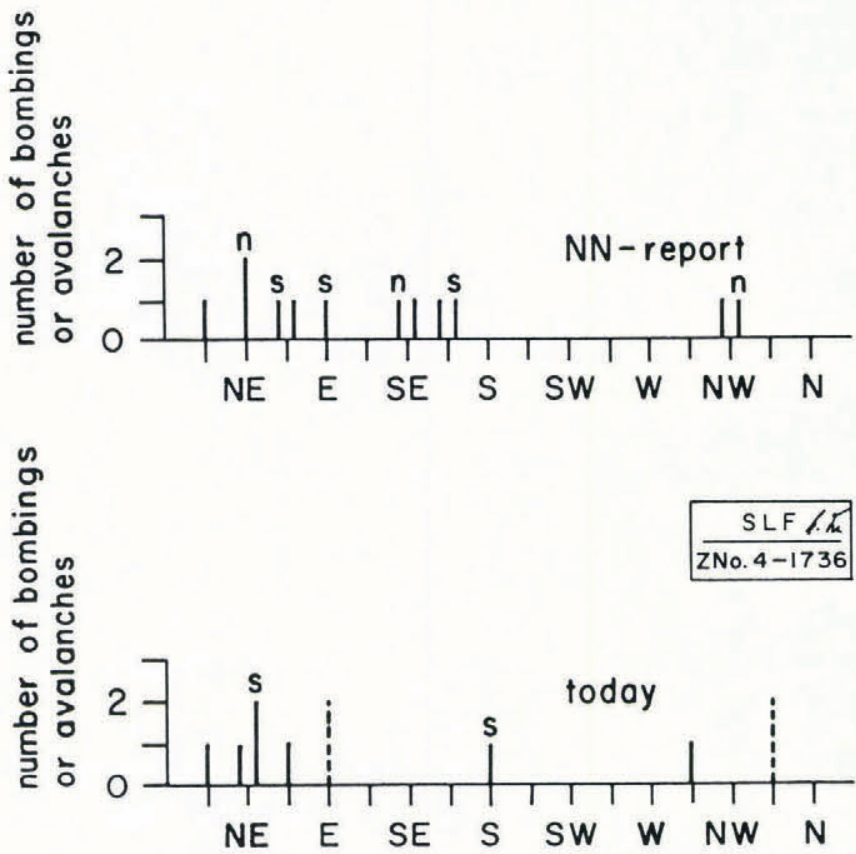

Fig. 3. Frequency of reported avalanche activities on 10 March 1988 plotted against slope aspect. Full lines: avalanche released by blasting, or naturally ( $n$ ) or by skiers (s). Dotted lines: no avalanche despite blasting. NN-report: data as given for the ten nearest neighbours.
The situation seems to have been tempting for those willing to ski off-piste, but was rather treacherous.

It is appropriate here to comment that a changed pattern of behaviour will also change a database. In the last example above three avalanches had been released by skiers in previous years. Assuming that with the aid of this method we will be able to avoid such incidents, then for the very same situation no avalanches will be recorded and the day will eventually come when the nearest neighbour days have none recorded either. This is likely to be interpreted as a safe situation, whereas the data really means that we had no skiers caught in an avalanche because they were warned to avoid the treacherous slopes.

\section{CONCLUSION AND REMARKS}

For several years we have tried to introduce statistical methods giving probabilities of the occurrence of avalanches. These have not been of much help in practical work, or to the local security service, the Parsenndienst, or those who had to issue the avalanche bulletin, reporting avalanche risks for large areas of the region. In the sequel we have restricted ourselves to finding a method which would help those who are responsible for avalanche control in rather smaller areas. At present their action is based on experience and a sound feeling for the local situation. Their experience draws both consciously and unconciously on the past. NXD looks for similar situations in previous years and provides them with a record of the corresponding avalanche activity forecast, which seems to be the best we can do to help them. Armed with the list of avalanches they become aware of the actual situation and the examples from previous years refresh their memory and advise the younger members of the need to consider potentially dangerous sites. We have tested this method with the Parsenndienst for two years. The patrolmen and their director have been convinced by the effectiveness of this kind of help and as a consequence have acquired their own computer. For us this is proof enough that they are sure the investment will pay off, and they have readily discovered other advantages of the process, such as in ammunition accountancy. This by no means degrades the value of the original avalanche forecast, on the contrary it will help to solve a long standing problem: that of providing an accurate, detailed, and daily avalanche record.

There are still some minor problems, most of them human or logistic, such as the inconsistent use of site names by patrolmen and the need for daily measurements of weather and snow elements. Because the Parsenndienst can use the data collected by the Institute for Snow and Avalanche Research we have not developed our own experience in this respect so far as we might have done. Nevertheless it appears likely to be worthwhile to extend the use of the method, and it may be that the results obtained in doing this can be used in interpolation to cover areas which are not being so rigorously observed and monitored.

\section{REFERENCES}

Buser, O. 1983. Avalanche forecast with the method of nearest neighbours: an interactive approach. Cold Reg. Sci. Technol., 8(2), 155-163.

Obled, C. and W. Good. 1980. Recent developments of avalanche forecasting by discriminant analysis techniques: a methodological review and some applications to the Parsenn area (Davos, Switzerland). J. Glaciol., 25(92), 315-346. 